\title{
Choosing Wisely, the reasons for its success
}

\author{
Marco Bobbio ${ }^{1}$, Sandra Vernero ${ }^{2}$ \\ ${ }^{1}$ General Secretary Slow Medicine, Turin; ${ }^{2}$ Vice president Slow Medicine, coordinator Choosing Wisely, Turin, Italy
}

\begin{abstract}
The philosophy and the history of the International Choosing Wisely movement, launched in the U.S. in 2012, are described. It grew and spread beyond what it was anticipated at the beginning because there is a raising concern of the medical community regarding the appropriate use of procedures and treatments placed into the market before an adequate evaluation of risks and benefits. Not only healthcare providers, but also patients, citizens and politicians, are becoming aware of the consequences of inappropriate decisions and behaviors since inappropriateness has economic (waste of resources), clinical (risks), but also ethical implications. In Italy the movement was launched and still is coordinated by the Slow Medicine organization, that created the campaign Doing more does not mean doing better - Choosing Wisely Italy, which aimed to improve clinical appropriateness through the reduction of unnecessary tests and treatments and the dialogue between physicians and patients. Currently, 44 societies of physicians, nurses, pharmacists and physiotherapists identified 230 recommendations about tests, treatments and procedures commonly used in Italy's clinical practice that do not provide any benefit to most patients but may cause harm.
\end{abstract}

\section{Introduction}

The wide increase of the number of tests and treatments in the last decade raised the attention of the medical community regarding the appropriate use of procedures and treatments placed into the market before an adequate evaluation of risks and benefits. In many instances even well documented physicians do not have enough data

Correspondence: Dr. Marco Bobbio, General Secretary Slow Medicine, Via Pietra del Gallo 45, 10025 Pino Torinese (TO), Italy. Mobile: +39.388.6188631. E-mail: mbobbio51@gmail.com

Key words: Choosing Wisely; Slow Medicine; overprescription; overuse.

Received for publication: 29 May 2019.

Accepted for publication: 7 June 2019.

CC Copyright M. Bobbio and S. Vernero, 2019

Licensee PAGEPress, Italy

Monaldi Archives for Chest Disease 2019; 89:1104

doi: 10.4081/monaldi.2019.1104

This article is distributed under the terms of the Creative Commons Attribution Noncommercial License (by-nc 4.0) which permits any noncommercial use, distribution, and reproduction in any medium, provided the original author(s) and source are credited. to decide whether a test is useful, for what kind of patients, at what disease's stage, how much it would change the pretest probability in a range of uncertainty, and finally if it is more appropriate and more cost-effective than another test. Not only healthcare providers, but also patients, citizens and politicians are becoming aware of the consequences of inappropriate decisions and behaviors, since inappropriateness has economic (waste of resources), clinical (risks), but also ethical implications. We are fully aware of the enormous progress achieved by scientific medicine in the last decades, but we are also concerned about the risks of a medicine without limits and of the inappropriate use of powerful resources [1]. The attention of the medical community to the appropriateness of diagnostic and therapeutic procedures has increased in recent years, recognizing the need for a careful use of resources and for avoiding unnecessary and sometimes harmful medical tests, treatments and procedures. Overuse is a pervasive problem. Unnecessary services can harm patients both physically and psychologically, and waste resources [2]. For example, overprescription of antibiotics has important consequences, such as increasing antimicrobial-resistant bacteria; inappropriate use of surgery puts patients at risk of surgical complications. Overuse, duplication, and use of low-value care arise because of changing medical practices, conflicting evidence about what is effective, lack of coordination among providers, patient demand, malpractice concerns, as well as reimbursement systems that encourage medical services based on volume, not value.

\section{Choosing Wisely}

Those are the reasons why Choosing Wisely project was formally launched by ABIM Foundation in 2012, involving U.S. medical societies invited to identify five procedures that were overused and did not provide meaningful benefit for patients and focusing on supporting and stimulating conversations between patients and physicians about unnecessary tests, treatments, and procedures. Since its launch, the campaign has spread to more than 20 countries worldwide. This rapid growth appears largely due to the fact that the campaign is rooted in professionalism. Choosing Wisely is not focused on money but, rather it is focused on providing quality care and avoiding any harms associated with overtreatment and overdiagnosis. Choosing Wisely campaigns are led by physicians, but one of their primary objectives is to engage patients in making decisions about their own medical care [3]. A set of questions that patients are encouraged to ask their clinicians has been suggested:

What are the benefits?

What are the risks?

What are the alternatives?

What if I do nothing?

Choosing Wisely campaigns fit into a growing global movement to control national spending on health care while still 
providing high-value care to patients. The movement has received attention from the Organization for Economic Co-operation and Development (OECD), because it engages both patients and physicians [4]. The campaigns fit with the OECD's interest in the economic drivers of health system performance, and ongoing attempts to tackle wasteful spending. Collaboration with the OECD has led to the introduction of three indicators of overuse (the overall number of antibiotic prescriptions, prescriptions for long acting benzodiazepine, and CT exams), which align with Choosing Wisely recommendations across 15 countries, in the OECD Health at a Glance report. Evidence of variation across countries in their use of tests, treatments and procedures supports the need for implementation of the campaign's recommendations.

In Canada also medical students of 17 medical schools started a project (STARS - Students and Trainees Advocating for Resource Stewardship) to increase awareness and more curricular content about health care overuse. Students started a range of initiatives, including forming interest groups to advocate for changing the formal curriculum, organizing interprofessional conferences. Similar movements of students and young physicians were subsequently established in other Countries.

\section{Choosing Wisely Italy}

In Italy the Choosing Wisely campaign was launched and is coordinated by the Slow Medicine [5], an association founded in 2011 as a movement aimed to promote a care based on appropriateness, but within a relation of listening, dialogue and decision sharing with the patient.

The mission of Slow Medicine is synthetized by three key words: measured, because it acts with moderation, gradually and without waste; respectful, because it is careful in preserving the dignity and values of each person; and equitable, because it is committed to ensuring access to appropriate care for all [6].

In a short time, the association spreads at national and international level, gathering the needs of change of a growing number of health professionals, patients and citizens, committed to manage health problems with a new cultural and methodological paradigm [7,8]. In 2012, Slow Medicine launched the Doing more does not mean doing better - Choosing Wisely Italy campaign which aims to improve clinical appropriateness through the reduction of unnecessary tests and treatments and the dialogue between physicians and patients. Presently, 44 societies of physicians, nurses, pharmacists and physiotherapists identified 230 recommendations about tests, treatments and procedures commonly used in Italy's clinical practice that do not provide any benefit to most patients but may cause harm. Altroconsumo (an independent, non-profit consumers organization), also created documents for the general public in collaboration with health professionals, in line with the recommendations. In several hospitals, professionals identified unnecessary tests, treatments and procedures to discuss with the patient. Recently a project to optimize medication (deprescription) in overtreated elderly avoiding adverse effects and improving outcomes was launched in Italy. The goal of deprescribing is to reduce medication burden and maintain or improve quality of life. As it happens in Canada and in other Countries, in Italy students and young physicians are engaging in Choosing Wisely and are defining their recommendations.

An App was recently developed containing professionals' recommendations and documents for the general public, in order to disseminate them and facilitate their implementation.

\section{Conclusions}

The Choosing Wisely campaign has grown and spread beyond what was anticipated at the beginning, but there are significant challenges ahead to achieve widespread effect on the quality and safety of care [9]. Despite the diffusion of the Choosing Wisely campaign in more than 20 Countries, further efforts are needed to translate the many recommendations into behavioral changes with a multidisciplinary coordinated intervention [10]. The first step consists in publishing the recommendation of the Scientific Society as it was recently done by Warren et al. [11] for the recommendations defined by the Italian Association of Cardiac Prevention and Rehabilitation (GICR-IACPR).

Advancements in implementation and evidence showing the positive effect on clinical outcomes are necessary to build up on the success to date. Evidence-based medicine informs the clinician world view that success is determined by rigorous data showing an effect on outcomes. Thus it is important to demonstrate effectiveness in improving outcomes and making a difference on measures of quality and safety that matter to clinicians and patients. However, empowering patients to participate in decisions about the use of medical tests and procedures remains a challenge [12].

\section{References}

1. Colla CH. Swimming against the current - What might work to reduce low-value care? N Engl J Med 371;14:1280-3.

2. Brownlee S, Chalkidou K, Doust J, et al. Evidence for overuse of medical services around the world. Lancet 2017. Doi: 10.1016/S0140-6736(16)32585-5.

3. Levinson W, Born K, Wolfson D. Choosing Wisely Campaigns. A work in progress. JAMA 2018;319:1975-6.

4. OECD. Tackling wasteful spending on health. OECD Publishing, Paris; 2017. Doi: 10.1787/9789264266414-en

5. Bert G, Bobbio M, Bonaldi, A, et al. [Slow Medicine: perché una medicina sobria rispettosa e giusta?].[Book in Italian]. Slow Medicine Publ., Turin; 2018.

6. Bonaldi A, Vernero S. Slow medicine: un nuovo paradigma in medicina. Recenti Prog Med 2015;106:1-7.

7. Camerini F, Fabris E, Sinagra G. [Appropriatezza e dintorni. "Fare di più non significa fare meglio". Choosing Wisely: un impegno disatteso?].[Article in Italian]. G Ital Cardiol 2017;18:824-31.

8. Camerini F, Fabris E, Sinagra G. Appropriateness, inappropriateness and waste of resources: Unfulfilled expectations? Eur J Intern Med 2019;63:15-8.

9. Admon AJ, Gupta A, Williams M, et al. Appraising the evidence supporting Choosing Wisely recommendations. J Hosp Med 2018;13:688-91.

10. Warren M, Copetti R, Gaibazzi N, et al. Choosing wisely in cardiology: Five proposals from the Italian Association for Cardiovascular Prevention and Rehabilitation. Monaldi Arch Chest Dis 2019. doi: 10.4081/monaldi.2019.1049

11. Warren M, Copetti R, Gaibazzi N, et al. Choosing wisely in cardiology: Five proposals from the Italian Association for Cardiovascular Prevention and Rehabilitation. Monaldi Arch Chest Dis 2019;89:1049.

12. Born KB, Coulter A, Han A, et al. Engaging patients and the public in Choosing Wisely. BMJ Qual Saf 2017;26:687-91. doi: 10.1136/bmjqs-2017-006595. 